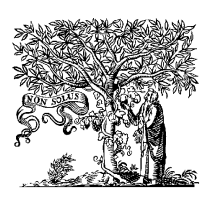

ELSEVIER

Fluid Phase Equilibria 173 (2000) 97-107

www.elsevier.nl/locate/fluid

\title{
Solubilities of some new refrigerants in water
}

\author{
Alexandre A.F. Miguel, Abel G.M. Ferreira, Isabel M.A. Fonseca* \\ Department of Chemical Engineering, University of Coimbra, Polo II, Pinhal de Marrocos, 3030-290 Coimbra, Portugal
}

Received 15 February 1999; accepted 30 May 2000

\begin{abstract}
Solubility data for the refrigerants $\mathrm{HFC} 23\left(\mathrm{CHF}_{3}\right), \mathrm{HFC} 32\left(\mathrm{CH}_{2} \mathrm{~F}_{2}\right)$ and $\mathrm{HFC} 125\left(\mathrm{C}_{2} \mathrm{HF}_{5}\right)$ in water have been determined as a function of the temperature in the range of temperatures $288-303 \mathrm{~K}$ at atmospheric pressure. These hydrofluorocarbons (HFCs) are good substitutes of the chlorofluorocarbons (CFCs), which have significant impact to stratospheric ozone depletion.

The $\phi-\phi$ approach has been used to predict the experimental results. The fugacity coefficients were calculated using a modified version of the Peng-Robinson equation of state. () 2000 Elsevier Science B.V. All rights reserved.

Keywords: Data; Solubility; Refrigerants; HFCs
\end{abstract}

\section{Introduction}

It has been proven that the halogenated chlorofluorocarbons (CFCs), which have been widely used as solvents, refrigerants, foaming agents and propellants have a strong ozone depletion potential, and enhance the greenhouse effect [1]. To protect the world's environment, it is urgent to develop alternatives to replace CFCs. The hydrocarbons that contain no chlorine, e.g. hydrofluorocarbons (HFCs) are considered as good candidates. The increasing need for information on the properties of these substances has led the authors to determine the solubilities of trifluoromethane (HFC23), difluoromethane (HFC32), and pentafluoroethane (HFC125) in water, in the temperature range 288-303 K at atmospheric pressure.

Van Ness and Abbott [2] have showed that the gas solubility problem is essentially a vapor-liquid equilibrium problem, therefore gas solubility data can be predicted either by the $\gamma-\phi$ (activity coefficientfugacity coefficient) method or the $\phi-\phi$ method. In this work, the second approach has been used to test the applicability of a modified version of the Peng-Robinson equation of state [3]. Since this well known cubic equation of state has been proven to correlate adequately vapor-liquid equilibrium data, we decided to verify its effectiveness to predict solubility data.

\footnotetext{
* Corresponding author. Tel.: +351-239798700; fax: +351-239798703.

E-mail address: fonseca@eq.uc.pt (I.M.A. Fonseca).
} 


\section{Experimental}

The apparatus and technique for the solubility measurements has been published in detail previously [4]. Anyway, in Fig. 1 we represent a schematic diagram to help to understand the experimental procedure. The principle of the method is to bring a measured volume of liquid into contact with a known volume of gas, at a given temperature and pressure. After equilibrium has been attained, the change in the gas volume yields the amount of gas dissolved in the liquid, and hence the solubility. The temperature of the liquid sample is measured with a platinum resistance thermometer (calibrated against a precision mercury thermometer graduated to $10 \mathrm{mK}$, as certified by NPL, UK). The mercury levels in the manometer are measured with a precision cathetometer (to $0.01 \mathrm{~mm}$ ). After the whole apparatus has been evacuated, the gas is introduced into the system. The working pressure is adjusted to the atmospheric pressure, and a sample of water is injected into the absorption vessel. After mechanical shaking for 10-15 min, the mercury is brought to level in the three tubing branches. The change in the mercury level on the right hand tube of the manometer is measured with a cathetometer later (at least $8 \mathrm{~h}$ ) to make sure that equilibrium has been attained.

The experimental accuracy of the present method examined by measuring the solubility of oxygen and carbon dioxide in water, is found being about 2\%. The comparison, shown in Fig. 2 between our experimental Henry constant values for these two systems and the literature ones indicates a very good agreement.

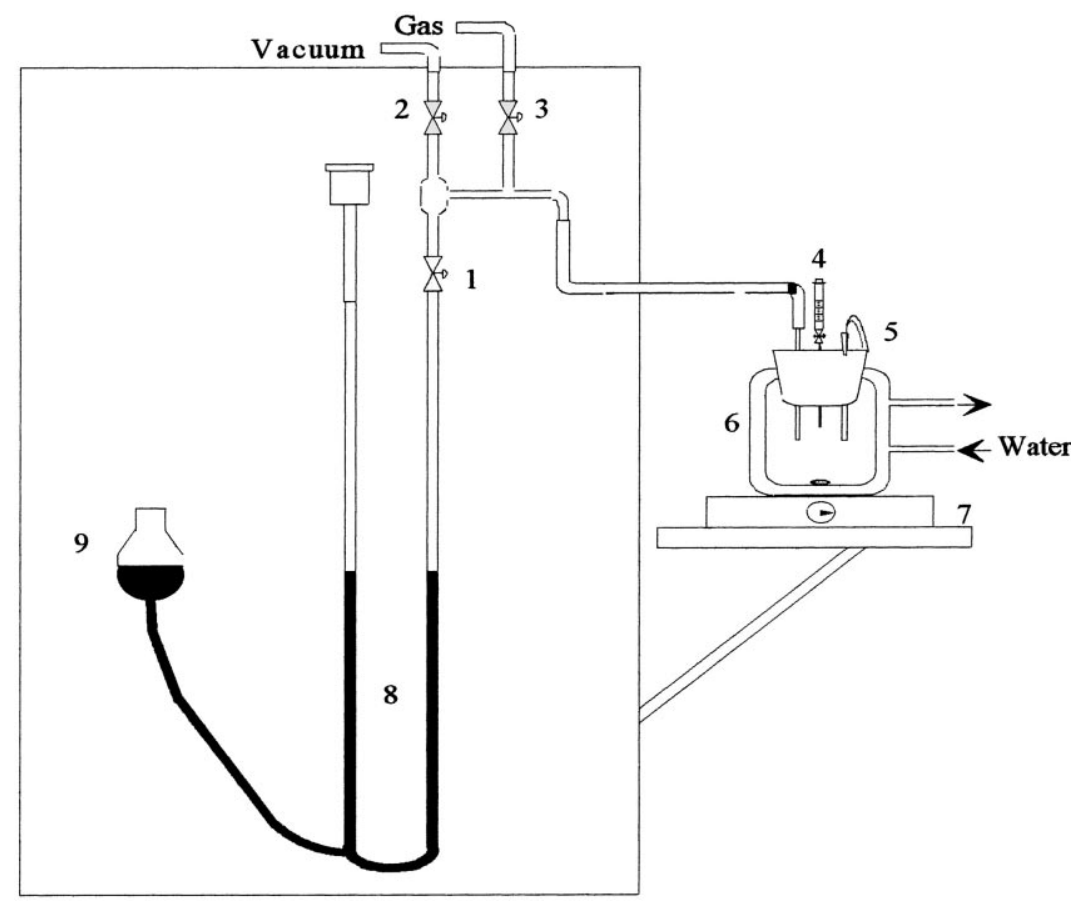

Fig. 1. Solubility apparatus: (1), (2) and (3) stopcocks; (4) liquid sample injector; (5) platinum resistance thermometer; (6) double walled absorption vessel; (7) magnetic stirrer; (8) mercury manometer and (9) mercury reservoir. 

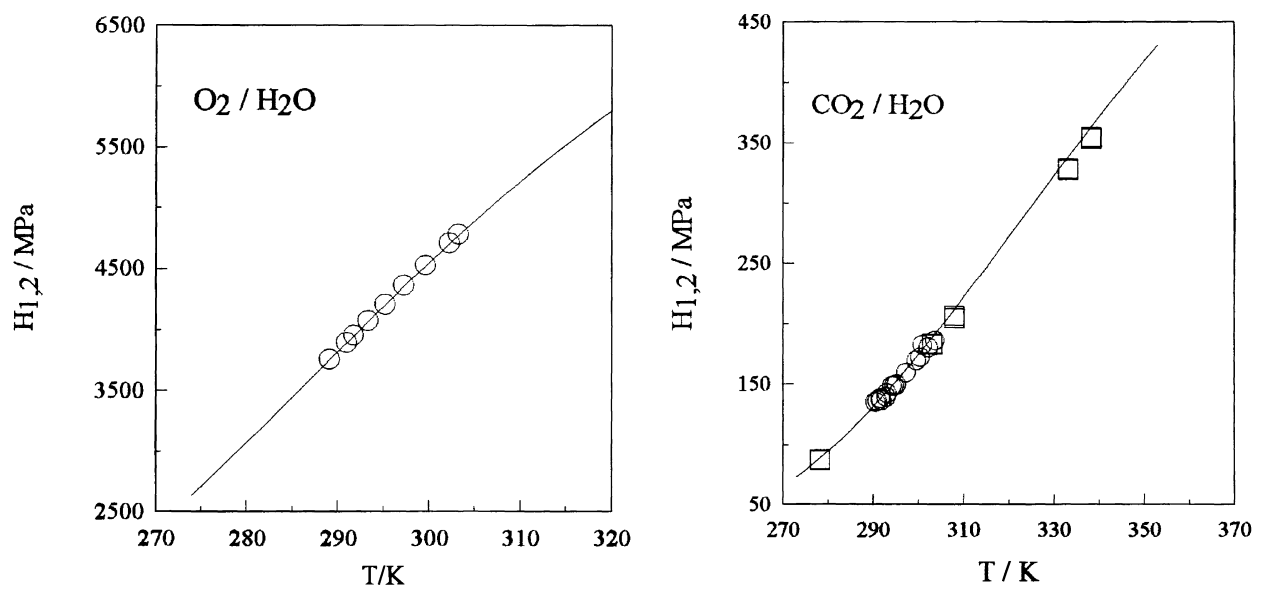

Fig. 2. Comparison of the measured and literature reported Henry coefficients $\left(H_{2,1}(\mathrm{MPa})\right)$ for the carbon dioxide and for the oxygen+water systems: $(\bigcirc)$ this work; $(\square)$ Zheng et al. [5]; (-) Wilhelm et al. [6].

The hydrofluorocarbons used in this work, obtained from Linde Gas, were of the the highest purity available $(99.9 \mathrm{~mol} \%)$. The purified water has been degassed using a combination of the techniques described by Gibbs and Van Ness [7] and Bell et al. [8].

\section{Calculations}

To treat the raw data, we have made the following assumptions: (i) the volume change of the liquid sample during saturation is negligible; (ii) the gases follow the truncated virial equation to the second term; (iii) Raoult's law is valid for the solvent in this mixture; and (iv) the system obeys the Henry's law.

The volume of the absorbed gas $\left(V_{2}\right)$ is given by:

$$
V_{2}=V_{1}-\Delta V,
$$

where $V_{1}$ is the volume of the pure liquid sample injected in the absorption vessel, and $\Delta V$ is the measured volume change of the gas after the equilibrium has been attained. The quantity (in mol) of gas absorbed in the liquid is obtained by

$$
n_{2}=\frac{V_{2}}{V_{\mathrm{m}}^{\mathrm{G}}}
$$

where

$$
V_{\mathrm{m}}^{\mathrm{G}}=\frac{R T}{P_{2}}+B
$$

and

$$
P_{2}=P-\left(1-x_{2}\right) P_{1}^{*} \text {. }
$$

$V_{\mathrm{m}}^{\mathrm{G}}$ is the molar volume of the gas at the equilibrium temperature T. $P$ denotes the equilibrium pressure and $x_{2}$ the solubility, in mole fraction, of the gas in the liquid solution. $P_{1}^{*}$ is the vapor pressure of the 
Table 1

Critical constants, $T_{\mathrm{c}}, P_{\mathrm{c}}$ and $V_{\mathrm{c}}$ of the pure substances

\begin{tabular}{llcr}
\hline Substance & $T_{\mathrm{c}}(\mathrm{K})$ & $P_{\mathrm{c}}(\mathrm{MPa})$ & $V_{\mathrm{c}}\left(\mathrm{cm}^{3} \mathrm{~mol}^{-1}\right)$ \\
\hline $\mathrm{H}_{2} \mathrm{O}$ & $647.10^{\mathrm{a}}$ & $22.064^{\mathrm{a}}$ & $55.83^{\mathrm{a}}$ \\
$\mathrm{HFC} 23$ & $298.98^{\mathrm{b}}$ & $4.820^{\mathrm{c}}$ & $133.11^{\mathrm{b}}$ \\
$\mathrm{HFC} 32$ & $351.255^{\mathrm{d}}$ & $5.784^{\mathrm{d}}$ & $122.70^{\mathrm{d}}$ \\
$\mathrm{HFC125}$ & $339.165^{\mathrm{d}}$ & $3.620^{\mathrm{d}}$ & $211.305^{\mathrm{d}}$ \\
\hline
\end{tabular}

${ }^{\mathrm{a}}[9]$.

${ }^{\mathrm{b}}$ [13] (as reported by McLinden [14]).

${ }^{c}[14]$.

${ }^{\mathrm{d}}$ [15] (as reported by Widiatmo et al. [16]).

pure solvent, calculated from the Wagner equation with coefficients determined by regression to fit the most probable values of vapor pressure [9].

All the solubilities have been corrected to 1 atm partial pressure using the Henry's law. $B$ in Eq. (3) is the second virial coefficient of the gas at the equilibrium temperature. An equation of the type

$$
\frac{B}{V_{\mathrm{c}}}=\sum_{i} b_{i}\left(\frac{T}{T_{\mathrm{c}}}\right)^{-i},
$$

where $V_{\mathrm{c}}$ and $T_{\mathrm{c}}$ represent the critical volume and the critical temperature, respectively, has been used with $b_{i}$ adjusted to the values of the compiled second virial coefficients. Which concerns $\mathrm{C}_{2} \mathrm{HF}_{5}$, we have used a correlation for $B$ given by Zhang et al. [10]. For $\mathrm{CHF}_{3}$, we have used the data of Dymond and Smith [11] and the experimental values from Bignell and Dunlop [12], which are in agreement with the first. For $\mathrm{CH}_{2} \mathrm{~F}_{2}$, the latter data source was selected. In Table 1, we present the critical constants of pure substances and in Table 2, we give the fitted parameters of Eq. (5).

The dependence of the solubility of the hydrofluorocarbons on temperature ( $T$, in $\mathrm{K})$ have been represented by the equation:

$$
R \ln x_{2}=A_{0}+\frac{A_{1}}{T}
$$

with the parameters fitted to the data by the least-squares method.

The thermodynamic functions of the solution have been obtained from Eq. (6) by standard expressions

$$
\Delta H_{2}^{0}=R T\left(\frac{\partial \ln x_{2}}{\partial \ln T}\right)_{P_{2}}=-A_{1}
$$

Table 2

Fitted constants of Eq. (5) for the gases

\begin{tabular}{lrrr}
\hline Gas & \multicolumn{1}{c}{$b_{0}$} & $b_{1}$ & $b_{2}$ \\
\hline HFC23 & -1.8085 & 3.2121 & -2.8007 \\
HFC32 & 3.8772 & -5.3324 & - \\
\hline
\end{tabular}




$$
\Delta S_{2}^{0}=R\left[\left(\frac{\partial \ln x_{2}}{\partial \ln T}\right)_{P_{2}}+\ln x_{2}\right]=A_{0},
$$

and

$$
\Delta G_{2}^{0}=\Delta H_{2}^{0}-T \Delta S_{2}^{0} .
$$

A modified version of Peng-Robinson equation of state has been used to predict the solubility data obtained for the three systems. This cubic equation of state has the functional form

$$
P=\frac{R T}{V-b}-\frac{a \alpha(T)}{V(V+b)+b(V-b)},
$$

where

$$
a=0.45724 \frac{R^{2} T_{\mathrm{c}}^{2}}{P_{\mathrm{c}}},
$$

and

$$
b=0.07780 \frac{R T_{\mathrm{c}}}{P_{\mathrm{c}}} .
$$

For the temperature dependence of the attractive parameter $\alpha$, we have used the form proposed by Melhem et al. [3],

$$
\ln \alpha=m\left[1-\frac{T}{T_{\mathrm{c}}}\right]+n\left[1-\sqrt{\frac{T}{T_{\mathrm{c}}}}\right]^{2},
$$

where $m$ and $n$ are adjustable parameters calculated by regressing experimental vapor pressure data in the whole vapor-liquid equilibrium range. This procedure allows us to predict accurate values of the vapor pressure of the pure components; this is especially important for the solvent, when we are modeling gas solubility with EOS.

The mixture parameters have been calculated using the van der Waals one-fluid mixing rules

$$
\begin{aligned}
a & =\sum_{i} \sum_{j} x_{i} x_{j} a_{i j}, \\
b & =\sum_{i} x_{i} b_{i},
\end{aligned}
$$

where $a_{i j}$ was determined from the following combining rule:

$$
a_{i j}=\left(1-k_{i j}\right) a_{i}^{0.5} a_{j}^{0.5},
$$

where $k_{i j}$ is a binary interaction parameter, which has been optimized for each temperature using a iterative procedure consisting in a FLASH calculation. With this procedure, we get the compositions of the liquid and vapor phases, $\left(x_{1}, x_{2}\right)$ and $\left(y_{1}, y_{2}\right)$, respectively, at the given conditions $(T, P$ and feed mole fractions, $z_{i}$ ). The equilibrium constant, $K_{i}$, of each component is calculated by the ratio:

$$
K_{i}=\frac{\phi_{i}^{\mathrm{L}}}{\phi_{i}^{\mathrm{G}}}
$$


Table 3

Fitted parameters of Eq. (19) and average percentual deviations of the Henry constant, $\sigma\left(H_{2,1}\right)$, Eq. (20)

\begin{tabular}{|c|c|c|c|c|}
\hline System & $m_{1}$ & $m_{2}$ & $m_{3}$ & $\sigma\left(H_{2,1}\right)(\%)$ \\
\hline $\mathrm{HFC} 23(2) / \mathrm{H}_{2} \mathrm{O}(1)$ & 0.0066 & -97.3 & - & 0.5 \\
\hline $\mathrm{HFC} 32(2) / \mathrm{H}_{2} \mathrm{O}(1)$ & 5.5651 & -3247.9 & 459906 & 0.4 \\
\hline $\mathrm{HFC} 125(2) / \mathrm{H}_{2} \mathrm{O}(1)$ & 3.4124 & -2188.3 & 310191 & 0.8 \\
\hline
\end{tabular}

The fugacity coefficients, $\phi_{i}^{\mathrm{L}}$ and $\phi_{i}^{\mathrm{G}}$ are obtained using the modified Peng-Robinson equation of state. Finally the Henry constant, $H_{2,1}$, is given by

$$
H_{2,1}=\lim _{x_{2} \rightarrow 0}\left[\frac{\phi_{2}^{\mathrm{G}} P y_{2}}{x_{2}}\right]
$$

which will be compared with the experimental value. The parameter $k_{12}$ has been considered temperature dependent, and has been evaluated by the following empirical correlation [5],

$$
k_{12}=m_{1}+\frac{m_{2}}{T}+\frac{m_{3}}{T^{2}} .
$$

The regression constants $m_{1}, m_{2}$ and $m_{3}$ are given in Table 3, with the average percentual deviation of the Henry constant,

$$
\sigma\left(H_{2,1}\right)=\frac{1}{M}\left[\sum \frac{\mid H_{2,1}(\exp )-H_{2,1}(\text { calc }) \mid}{H_{2,1}(\exp )}\right] \times 100,
$$

where $M$ represents the number of experimental data points and where $H_{2,1}$ decrease the space (calc) is obtained from the FLASH calculation using $k_{12}$ parameter calculated from Eq. (19).

\section{Results and discussion}

The solubilities of the hydrofluorocarbons in water are reported in terms of Ostwald coefficient, the Henry coefficient, and the mole fraction in Table 4 . The Ostwald coefficient, $L_{2,1}$, is defined as the ratio of the volume of gas absorbed to the volume of the absorbing liquid, both volumes being measured at the same temperature.

The solubility data are plotted in Fig. 3, showing that the solubility of HFC32 and HFC125 are quite similar and that of HFC23 is much smaller.

The experimental Gibbs energies, enthalpies and entropies of solution at $298 \mathrm{~K}$ calculated from Eqs. (7)(9) for the systems studied in this work are recorded in Table 5.

As far as we know, there are no experimental solubility data for HFC32 and HFC125 in water. What concerns the $\mathrm{HFC} 23 / \mathrm{H}_{2} \mathrm{O}$ system we have found in the literature solubility values in the range (298-348 K) [6] and in the range (278-338 K) [5]. In Fig. 4, we can compare our experimental results with the literature ones. In the common range of temperature, we see that our values are lower than the others, but as the temperature decreases they become closer. Actually, the figure stresses the need of more experimental solubility data for this system. 
Table 4

Solubilities of HFC23, HFC32 and HFC125 in water expressed as mole fraction, $x_{2}$ at a partial pressure $P_{2}=101325 \mathrm{~Pa}$, Ostwald coefficient, $L_{2,1}$ at $P_{2}=101325 \mathrm{~Pa}$, and Henry coefficient, $H_{2,1}$.

\begin{tabular}{|c|c|c|c|c|}
\hline Gas & $T(\mathrm{~K})$ & $x_{2} \times 10^{4}$ & $L_{2,1}$ & $\begin{array}{l}H_{2,1} \\
(\mathrm{MPa})\end{array}$ \\
\hline \multirow[t]{16}{*}{$\mathrm{HFC} 23$} & 288.30 & 5.067 & 0.660 & 200.0 \\
\hline & 290.55 & 4.800 & 0.630 & 211.1 \\
\hline & 291.55 & 4.685 & 0.617 & 216.3 \\
\hline & 292.30 & 4.608 & 0.608 & 219.9 \\
\hline & 293.15 & 4.437 & 0.587 & 228.4 \\
\hline & 293.67 & 4.367 & 0.579 & 232.0 \\
\hline & 294.30 & 4.308 & 0.572 & 235.2 \\
\hline & 295.25 & 4.157 & 0.554 & 243.8 \\
\hline & 296.00 & 4.089 & 0.546 & 247.8 \\
\hline & 297.08 & 3.961 & 0.531 & 255.8 \\
\hline & 297.60 & 3.891 & 0.522 & 260.4 \\
\hline & 298.38 & 3.823 & 0.514 & 265.0 \\
\hline & 299.68 & 3.681 & 0.497 & 275.3 \\
\hline & 300.50 & 3.596 & 0.487 & 281.8 \\
\hline & 301.49 & 3.485 & 0.473 & 290.7 \\
\hline & 303.03 & 3.377 & 0.461 & 300.2 \\
\hline \multirow[t]{14}{*}{ HFC32 } & 289.16 & 7.584 & 0.985 & 133.6 \\
\hline & 290.50 & 7.305 & 0.953 & 138.7 \\
\hline & 291.29 & 7.107 & 0.930 & 142.6 \\
\hline & 292.35 & 6.898 & 0.906 & 146.9 \\
\hline & 293.14 & 6.743 & 0.888 & 150.3 \\
\hline & 294.20 & 6.407 & 0.847 & 158.1 \\
\hline & 294.99 & 6.238 & 0.827 & 162.4 \\
\hline & 296.04 & 5.998 & 0.798 & 168.9 \\
\hline & 297.08 & 5.689 & 0.759 & 178.1 \\
\hline & 298.12 & 5.452 & 0.730 & 185.9 \\
\hline & 298.90 & 5.358 & 0.719 & 189.1 \\
\hline & 299.94 & 5.049 & 0.680 & 200.7 \\
\hline & 301.23 & 4.743 & 0.641 & 213.6 \\
\hline & 302.26 & 4.469 & 0.606 & 226.7 \\
\hline \multirow[t]{14}{*}{ HFC125 } & 289.16 & 7.691 & 0.996 & 131.7 \\
\hline & 290.13 & 7.639 & 0.992 & 132.6 \\
\hline & 291.03 & 7.539 & 0.982 & 134.4 \\
\hline & 292.09 & 7.153 & 0.935 & 141.7 \\
\hline & 293.14 & 6.943 & 0.911 & 145.9 \\
\hline & 294.20 & 6.686 & 0.881 & 151.6 \\
\hline & 294.99 & 6.430 & 0.849 & 157.6 \\
\hline & 296.15 & 6.300 & 0.835 & 160.8 \\
\hline & 297.34 & 5.832 & 0.776 & 173.7 \\
\hline & 299.16 & 5.570 & 0.746 & 181.9 \\
\hline & 299.94 & 5.344 & 0.717 & 189.6 \\
\hline & 301.23 & 5.045 & 0.680 & 200.8 \\
\hline & 302.01 & 4.852 & 0.656 & 208.8 \\
\hline & 303.03 & 4.704 & 0.638 & 215.4 \\
\hline
\end{tabular}




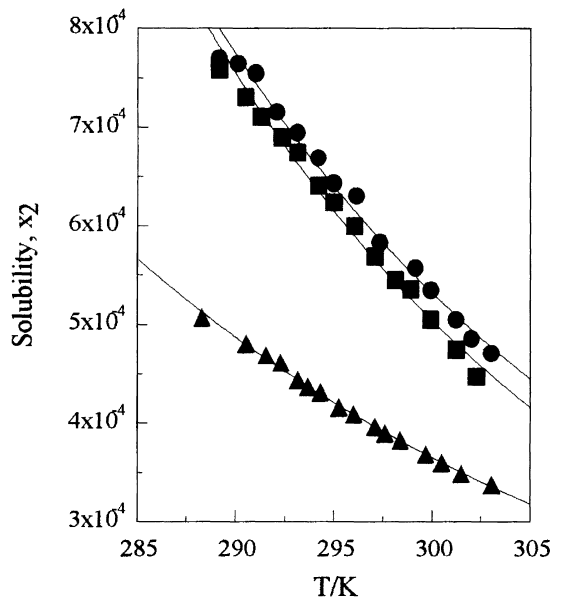

Fig. 3. Solubilities of trifluoromethane $(\boldsymbol{\Delta})$, difluoromethane $(\boldsymbol{\square})$, and pentafluoroethane $(\mathbf{O}), x_{2}$, in mole fraction, in water, as a function of the temperature, $T(\mathrm{~K})$.

Table 5

Molar Gibbs energy of solution $\Delta G_{2}^{0}$, enthalpy of solution $\Delta H_{2}^{0}$ and entropy of solution ${ }^{\mathrm{a}} \Delta S_{2}^{0}$

\begin{tabular}{|c|c|c|c|}
\hline System & $\Delta H_{2}^{0}\left(\mathrm{~J} \mathrm{~mol}^{-1}\right)$ & $\Delta S_{2}^{0}\left(\mathrm{~J} \mathrm{~mol}^{-1} \mathrm{~K}^{-1}\right)$ & $\Delta G_{2}^{0}\left(\mathrm{~J} \mathrm{~mol}^{-1}\right)$ \\
\hline $\mathrm{HFC} 23 / \mathrm{H}_{2} \mathrm{O}$ & -20861 & -135.35 & 19493 \\
\hline $\mathrm{HFC} 32 / \mathrm{H}_{2} \mathrm{O}$ & -27180 & -153.29 & 18523 \\
\hline $\mathrm{HFC} 125 / \mathrm{H}_{2} \mathrm{O}$ & -29205 & -160.48 & 18643 \\
\hline
\end{tabular}

${ }^{\text {a }}$ At $298 \mathrm{~K}$ and $1 \mathrm{~atm}$ partial pressure of the gases.

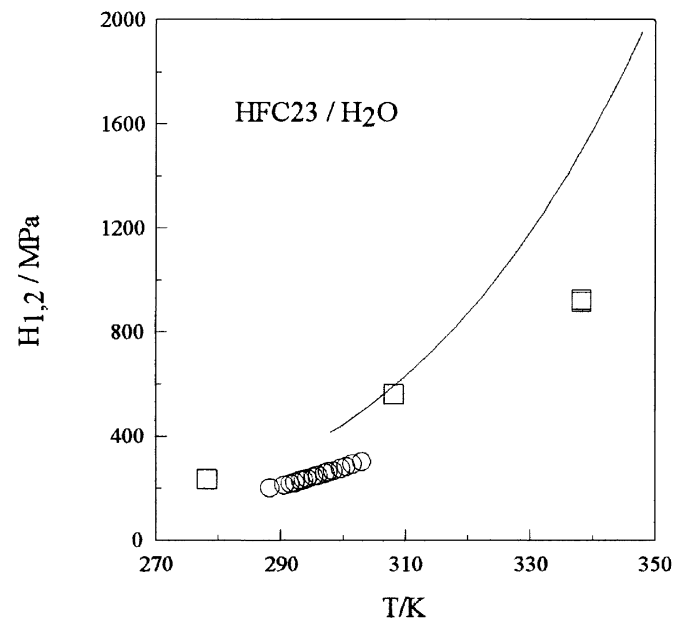

Fig. 4. Comparison of the measured and literature reported Henry coefficients $\left(H_{2,1}(\mathrm{MPa})\right)$ for the $\mathrm{H}_{2} \mathrm{O}(1)+\mathrm{HFC} 23(2)$ system: ( $\square)$, Zheng et al. [5]; (○), this work; (-), Wilhelm et al. [6]. 
Table 6

Parameters in the equation $R \ln x_{2}=A_{0}+A_{1} / T^{\mathrm{a}}$

\begin{tabular}{lllll}
\hline System & $A_{0}\left(\mathrm{~J} \mathrm{~K}^{-1} \mathrm{~mol}^{-1}\right)$ & $A_{1}\left(\mathrm{~J} \mathrm{~mol}^{-1}\right)$ & $\sigma(\%)$ & $\sigma\left(H_{2,1}\right)(\%)$ \\
\hline $\mathrm{HFC} 23 / \mathrm{H}_{2} \mathrm{O}$ & -135.348 & 20860.7 & 0.4 & 0.4 \\
$\mathrm{HFC} 32 / \mathrm{H}_{2} \mathrm{O}$ & -160.480 & 29204.5 & 1 & 1 \\
$\mathrm{HFC} 125 / \mathrm{H}_{2} \mathrm{O}$ & -153.287 & 27180.1 & 1 & 1 \\
\hline
\end{tabular}

${ }^{\mathrm{a}} \sigma$ is the average percentual deviation of $x_{2},\left(\sigma=(1 / M)\left[\sum\left|x_{2}(\exp )-x_{2}(\mathrm{calc})\right| / x_{2}(\exp )\right] \times 100\right.$, where $M$ is the number of experimental points) and $\sigma\left(H_{2,1}\right)$ represents the average percentual deviation of the Henry constant, Eq. (20).

To represent the temperature dependence of the mole fraction solubilities, Eq. (6) was fitted to the corrected $x_{2}$ values. The optimized parameters of Eq. (6) and the average percentual deviation of $x_{2}$, are listed in Table 6. In this table we present also the average percentual deviation of the Henry constant obtained by Eq. (20). $H_{2,1}$ (calc) was obtained by the Henry's law, with $x_{2}$ calculated by Eq. (6).

The modified PREOS can model quite well the experimental solubility data. Negative values of the $k_{12}$ binary interaction parameters are obtained as we can see in Fig. 5. The optimized coefficients of Eq. (19) are shown in Table 3. For the systems HFC32 and $\mathrm{HFC} 125 / \mathrm{H}_{2} \mathrm{O}$, we have three coefficients to obtain average deviations of the Henry constant of the order of magnitude of that of the system $\mathrm{HFC} 23 / \mathrm{H}_{2} \mathrm{O}$. We have found that using three decimals in the values of $k_{12}$ calculated from Eq. (19) the average percentual deviation of the Henry constant is less than $1 \%$.

The calculation of the Henry constant with an EOS can be made in a equivalent way using the well known expression

$$
H_{2,1}=\varphi_{2}^{\mathrm{L}, \infty} P_{1}^{*}
$$
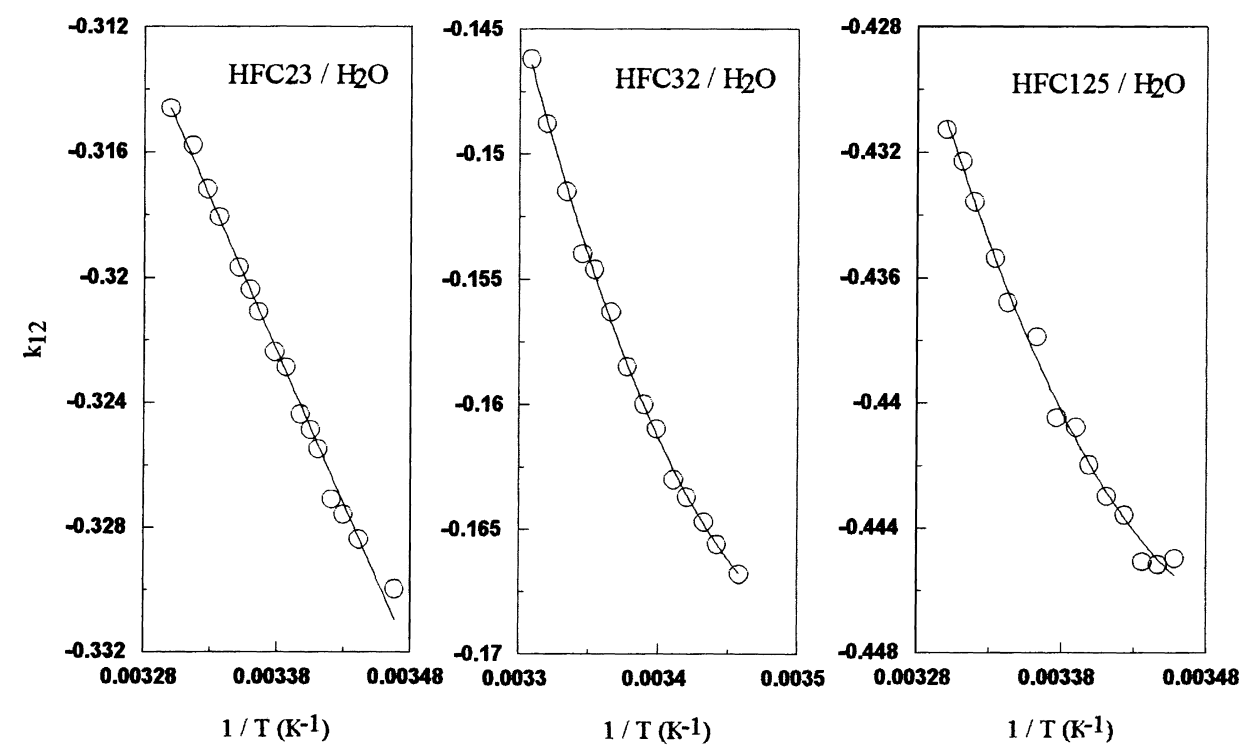

Fig. 5. Binary interaction parameter $k_{12}$ as a function of temperature, (1/T). The symbols indicate the calculated values from the modified PREOS and the lines the calculated values from Eq. (19). 
Table 7

Fitted parameters of Eq. (13) and average percentual deviations of the vapor pressure ${ }^{\mathrm{a}}$

\begin{tabular}{lllll}
\hline Substance & $m$ & $n$ & $\sigma(P)(\%)$ & Reference \\
\hline $\mathrm{H}_{2} \mathrm{O}$ & 0.8859 & 0.0268 & 0.7 & {$[9]$} \\
$\mathrm{HFC} 23$ & 0.7530 & 0.3293 & 0.4 & {$[17]$} \\
& & & & {$[18]$} \\
HFC32 & & & 0.9 & {$[19]$} \\
$\mathrm{HFC125}$ & 0.7754 & 0.2610 & 0.2 & {$[20]$} \\
& 0.8155 & 0.2439 & & {$[21]$} \\
\hline
\end{tabular}

${ }^{\mathrm{a}} \sigma(P)=(1 / M)\left[\sum \mid P(\exp )-P(\right.$ calc $\left.) \mid / P(\exp )\right] \times 100$, where $M$ is the number of experimental points.

where $\varphi_{2}^{\mathrm{L}, \infty}$ is the fugacity coefficient of the gas at infinite dilution in the liquid phase. We have realized that the latter procedure gives the same set of $k_{12}$ parameters. The Eq. (21) stresses the need of an adequate representation of $P_{1}^{*}$, which is achieved using a modified version of the PREOS with an improved function for $\alpha(T)$. In Table 7 we present the adjusted coefficients of Eq. (13) obtained from experimental vapor pressure data and the respective average percentual deviation, $\sigma(P)$, which is of the same order of magnitude for all the compounds.

\section{Conclusions}

New experimental high accuracy solubility data have been determined for some 'green' refrigerants (HFC23, HFC32, HFC125) in water, which can be alternatives of the widely used CFCs.

The Peng-Robinson equation of state in a modified form has proven to model quite well the experimental data using only one adjustable parameter $\left(k_{i j}\right)$ in the combining rule for the $a_{i j}$ constant.

\section{List of symbols}

$A_{0} \quad$ parameter in Eq. (6)

$A_{1} \quad$ parameter in Eq. (6)

$B \quad$ second virial coefficient $\left(\mathrm{cm}^{3} \mathrm{~mol}^{-1}\right)$

$\Delta G_{2}^{0} \quad$ molar Gibbs energy of solution $\left(\mathrm{J} \mathrm{mol}^{-1}\right)$

$H_{2,1} \quad$ Henry constant

$\Delta H_{2}^{0} \quad$ molar enthalpy of solution $\left(\mathrm{J} \mathrm{mol}^{-1}\right)$

$L_{2,1} \quad$ Ostwald coefficient

$n_{2} \quad$ amount of gas absorbed in the liquid (mol)

$P \quad$ pressure $(\mathrm{Pa})$

$P_{1}^{*} \quad$ vapor pressure of the pure solvent $(\mathrm{Pa})$

$P_{2} \quad$ partial pressure of the solute gas $(\mathrm{Pa})$

$R \quad$ gas constant $\left(\mathrm{J} \mathrm{mol}^{-1} \mathrm{~K}^{-1}\right)$

$\Delta S_{2}^{0} \quad$ molar entropy of solution $\left(\mathrm{J} \mathrm{mol}^{-1} \mathrm{~K}^{-1}\right)$

$T$ temperature (K)

$T_{c} \quad$ critical temperature $(\mathrm{K})$ 
$\Delta V \quad$ measured volume change in the gas $\left(\mathrm{cm}^{3}\right)$

$V_{c} \quad$ critical volume $\left(\mathrm{cm}^{3} \mathrm{~mol}^{-1}\right)$

$V_{\mathrm{m}}^{\mathrm{G}} \quad$ molar volume of gas $\left(\mathrm{cm}^{3} \mathrm{~mol}^{-1}\right)$

$V_{1} \quad$ volume of pure liquid $\left(\mathrm{cm}^{3}\right)$

$V_{2} \quad$ volume of the absorbed gas $\left(\mathrm{cm}^{3}\right)$

$x_{2} \quad$ mole fraction solubility

$\sigma \quad$ average percentual deviation

\section{References}

[1] P.S. Fialho, C.A. Nieto de Castro, Prediction of halocarbon liquid densities by a modified hard sphere-De Santis equation of state, Fluid Phase Equilibria 118 (1996) 103-114.

[2] H.C. Van Ness, M.M. Abbott, Classical Thermodynamics of Nonelectrolyte Solutions, McGraw-Hill, USA, 1982.

[3] G.A. Melhem, R.S. Saini, B.M. Goodwin, A modified Peng-Robinson equation of state, Fluid Phase Equilibria 47 (1989) 189-237.

[4] C.S.O. Silva, I.M.A. Fonseca, L.Q. Lobo, Solubility of methyl fluoride in some alcohols, Fluid Phase Equilibria 135 (1997) 137-144.

[5] D.-Q. Zheng, T.-M. Guo, H. Knapp, Experimental and modeling studies on the solubility of $\mathrm{CO}_{2}, \mathrm{CHClF}_{2}, \mathrm{CHF}_{3}, \mathrm{C}_{2} \mathrm{H}_{2} \mathrm{~F}_{4}$ and $\mathrm{C}_{2} \mathrm{H}_{4} \mathrm{~F}_{2}$ in water and aqueous $\mathrm{NaCl}$ solutions under low pressures, Fluid Phase Equilibria 129 (1997) 197-209.

[6] E. Wilhelm, R. Battino, R.J. Wilcock, Low-pressure solubility of gases in liquid water, Chem. Rev. 77 (1977) $219-262$.

[7] R.E. Gibbs, H.C. Van Ness, Vapor-liquid equilibria from total pressure measurements. A new apparatus, Ind. Eng. Chem. Fundam. 11 (1972) 410-413.

[8] T.N. Bell, E.L. Cussler, K.R. Harris, C.N. Pepela, P.J. Dunlop, An apparatus for degassing liquids by vacuum sublimation, J. Phys. Chem. 72 (1968) 4693-4695.

[9] H. Sato, M. Vematsu, K. Watanabe, A. Saul, W. Wagner, New international tables for the thermodinamic properties of ordinary water substance, J. Phys. Chem. Ref. Data 17 (1988) 1439-1540.

[10] H.-L. Zhang, S. Tada, H. Sato, K. Watanabe, PVTx properties in the gas phase for binary R-125/143a system, Fluid Phase Equilibria 150-151 (1998) 333-341.

[11] J.H. Dymond, E.B. Smith, The Virial Coefficients of Pure Gases and Mixtures, Clarendon Press, Oxford, 1980.

[12] C.M. Bignell, P.J. Dunlop, Second virial coefficients for fluoromethanes and their binary mixtures with helium and argon, J. Chem. Eng. Data 38 (1993) 139-140.

[13] A.M. Shavandrin, Deposited documents, Vsesayuznui Nauchnoisseldovateliski Institut, Moscow no. 19-76, 1975.

[14] M.O. McLinden, Thermodynamic properties of CFC alternatives: a survey of the available data, Rev. Int. Froid 13 (1990) $149-162$.

[15] S. Kuwabara, J. Tatoh, H. Sato, K. Watanabe, in: Proceedings of the 13th Jpn. Thermophys. Prop. Symp., Akita, 1992, p. 69.

[16] J.V. Widiatmo, H. Sato, K. Watanabe, Saturated liquid densities and vapor pressures of the 1,1,1-trifluoroethane, difluoromethane, and pentafluoroethane, J. Chem. Eng. Data 39 (1994) 304-308.

[17] Y.C. Hon, J.J. Martin, Physical and thermodynamic properties of trifluorometane, AIChE J. 5 (1959) 125-129.

[18] R.H. Valentine, G.E. Brodale, W.F. Giauque, Trifluoromethane: entropy, low temperature heat capacity, heats of fusion and vaporization, and vapor pressure, J. Phys. Chem. 66 (1962) 392-395.

[19] A. Popowicz, O. Takao, J. Shulman, T. Ishida, Vapor pressure isotope effects in liquid fluoroform, J. Chem. Phys. 76 (1982) 3732-3743.

[20] R. Tillner-Roth, A. Yokozeki, An international standard equation of state for difluoromethane (R-32) for temperatures from the triple point at 136.34-435 K and pressures up to 70 MPa, J. Phys. Chem. Ref. Data 26 (1997) 1273-1328.

[21] L.A. Weber, A.M. Silva, Measurements of the vapor pressures of difluoromethane, 1-cloro-1,2,2,2-tetrafluoroethane and pentafluoroethane, J. Chem. Eng. Data 39 (1994) 808-812. 